\title{
Structural and isotopic reordering in Magnesite: Insights from heating experiments
}

\author{
SURJYENDU BHATTACHARJEE ${ }^{1 *}$, URI RYB ${ }^{2}$, JOHN M. \\ EILER $^{1}$ AND PAUL D. ASIMOW ${ }^{1}$ \\ ${ }^{1}$ California Institute of Technology, Pasadena, CA, USA \\ (*correspondence: sbhattac@ caltech.edu) \\ ${ }^{2}$ Hebrew University of Jerusalem, Jerusalem, Israel
}

The mineral magnesite $\left(\mathrm{MgCO}_{3}\right)$ has received less research attention than other carbonate minerals, despite its widespread occurrence from Earth's mantle to the surface of Mars. Magnesite forms in a variety of terrestrial environments (for example, subduction zone talc-magnesites, altered ophiolitic listvenites, low- $T$ precipitates in lakes and playas, magnesian marble) despite kinetic barriers to its precipitation at low $T$. Understanding its genesis requires a means to measure its temperature of formation. Clumped isotope thermometry allows one to determine formation temperature of any carbonate mineral based on the abundance of associated heavy ${ }^{18} \mathrm{O}$ and ${ }^{13} \mathrm{C}$ atoms in the same carbonate group (measured as mass $47 \mathrm{CO}_{2}$ ) relative to a stochastic distribution. Primary clumped isotopic signature recorded during mineral crystallization may become altered upon heating during burial and exhumations if isotopic reordering occurs. We assessed the stability of primary isotopic ordering in magnesites by heating a cryptocrystalline magnesite in a cold-seal apparatus at $719^{\circ} \mathrm{C}$ and $511^{\circ} \mathrm{C}$ under $\mathrm{P}_{\mathrm{CO} 2}$ of $1 \mathrm{~kb}$ for times from 0.1 to 100 hours. Even in the most extreme heating schedule $\left(100\right.$ hours at $\left.719^{\circ} \mathrm{C}\right)$, clumped isotope composition has remained far from equilibrium at the temperature of heating, indicating that the rate of solid state reordering in magnesite is significantly slower than in calcite or dolomite. This feature makes magnesite more resistant to clumped-isotope resetting than other well studied carbonates. The slow reordering rate can be attributed to the strength of the Mg-O bond. Powder X-Ray Diffraction study of the experimental products also reveals changes in the structure of cryptocrystalline magnesite during prolonged heating at high $T$ (reflected in XRD peak shifts and decreasing peak widths). Comparison with a crystalline (optical grade) magnesite shows that the achievement of crystalline order remains incomplete after 100 hours at $719^{\circ} \mathrm{C}$. The structural ordering is correlated in time with the clumped isotope reordering. We are conducting further experiments to detail the rates of structural and isotopic reordering in magnesite and the mechanistic relation between these two kinetic processes. 